\title{
Human Capital, Fertility and Growth ${ }^{1}$
}

\author{
Oded Galor
}

\begin{abstract}
The demographic transition that swept the world in the past 140 years has been identified as one of the prime forces in the transition from stagnation to growth. The unprecedented increase in population growth during the early stages of industrialization was ultimately reversed. The rise in the demand for human capital in the second phase of industrialization brought about a significant reduction in fertility rates and population growth in various regions of the world, enabling economies to convert a larger share of the fruits of factor accumulation and technological progress into growth of income per capita.
\end{abstract}

JEL classification Numbers: O11, O14, O33, O40, J11, J13

\footnotetext{
${ }^{1}$ Prepared for the New Palgrave Dictionary of Economics - $2^{\text {nd }}$ edition (S. Duraluf and L. Blume, eds.)
} 


\section{Introduction}

The transition from stagnation to growth has been the subject of an intensive research in recent years. The rise in the demand for human capital and the associates decline in population growth have been identified as the prime forces in the movement from an epoch of stagnation to a state of sustained economic growth. They brought about a significant formation of human capital along with a reduction in fertility rates and population growth, enabling economies to convert a larger share of the fruits of factor accumulation and technological progress into growth of income per capita.

\section{Historical Evidence}

The evolution of economies over most of human history was marked by Malthusian stagnation. Technological progress and population growth were miniscule by modern standards and the average growth rate of income per capita was even slower due to the offsetting effect of population growth on the expansion of resources per capita. In the past two centuries, in contrast, the pace of technological progress increased significantly in association with the process of industrialization. Various regions of the world departed from the Malthusian trap and initially experienced a considerable rise in the growth rates of income per capita and population. Unlike episodes of technological progress in the pre-Industrial Revolution era that failed to generate sustained economic growth, the increasing role of human capital in the production process in the second phase of the Industrial Revolution ultimately prompted a demographic transition, liberating the gains in productivity from the counterbalancing effects of population growth. The decline in population growth and the associated advancement in technological progress and human capital formation paved the way for the emergence of the modern state of sustained economic growth.

The evolution of population growth in the world economy has been non-monotonic. The growth of world population was sluggish during the Malthusian epoch, creeping at an average annual rate of about $0.1 \%$ over the years 0-1820 (Maddison, 2001). The Western European take-off along with that of the Western Offshoots (i.e., United States, Canada, Australia and New Zealand) brought about a sharp increase in population growth in these regions. The world annual average rate of population growth increased gradually reaching $0.8 \%$ in the years $1870-1913$. The take-off of less developed regions and the significant increase in their income per capita generated a further increase in the world rate of population growth, despite the decline in population growth in Western Europe and the Western Offshoots, reaching a high level of $1.92 \%$ per year in the period 1950-1973. Ultimately, the onset of the demographic transition in less developed economies in the second half of the 20th century, reduced population growth to an average rate of $1.63 \%$ per year in the period 1973-1998.

The timing of the demographic transition differed significantly across regions. The reduction in population growth occurred in Western Europe, the Western Offshoots, and Eastern Europe towards the end of the 19th century and in the beginning of the 20th century, whereas Latin America and Asia experienced a decline in the rate of population growth only in the last decades of the 20th century. Africa's population growth, in contrast, has been rising steadily, although this pattern is likely to reverse in the near future due to the decline in fertility rates in this region since the 1980s.

The demographic transition in Western Europe occurred towards the turn of the 19th century. A sharp reduction in fertility took place simultaneously in several countries in the 1870s, and resulted in a more than a 30\% decline in fertility rates within a 50 year period. Over the period 
1875-1920, Crude Birth Rates declined by 44\% in England, 37\% in Germany, and 32\% in Sweden and Finland. A decline in mortality rates preceded the decline in fertility rates in most Western Europe. It began in England nearly 140 years prior to the decline in fertility and in Sweden and Finland approximately 100 years prior to the decline in fertility. The decline in fertility outpaced the decline in mortality rates and brought about a decline in the number of children who survived to their reproduction age.

A similar pattern characterizes mortality and fertility decline in less developed regions. Total Fertility Rate over the period 1960-1999 plummeted from 6 to 2.7 in Latin America, from 6.14 to 3.14 in Asia, and declined moderately from 6.55 to 5.0 in Africa, along with a sharp decline in infant mortality rates.

\section{Theories of the Demographic Transition}

\section{A. The Decline in Infant and Child Mortality}

The decline in infant and child mortality rates that preceded the decline in fertility rates in many developed countries, with the notable exceptions of France and the US, has been demographers' favorite explanation for the onset of the decline in fertility. Nevertheless, this viewpoint appears inconsistent with historical evidence. While it is highly plausible that mortality rates were among the factors that affected the level of fertility along human history, historical evidence does not lend credence to the argument that the decline in mortality rates accounts for the reversal of the positive historical trend between income and fertility.

The mortality decline in Western Europe started nearly a century prior to the decline in fertility and was associated initially with increasing fertility rates in some countries and non-decreasing fertility rates in others. In particular, the decline in mortality started in England in the 1730s and was accompanied by a steady increase in fertility rates until 1820. The significant rise in income per capita in the Post-Malthusian Regime apparently increased the desirable number of surviving offspring and thus, despite the decline in mortality rates, fertility increased significantly so as to reach this higher desirable level. The decline in fertility during the demographic transition occurred in a period in which this pattern of increased income per capita (and its potential effect on fertility) was intensified, while the pattern of declining mortality (and its adverse effect on fertility) maintained the trend that existed in the 140 years that preceded the demographic transition. The reversal in the fertility patterns in England as well as other Western European countries in the 1870s suggests therefore that the demographic transition was prompted by a different universal force than the decline in infant and child mortality.

Furthermore, most relevant from an economic point of view is the cause of the reduction in net fertility (i.e. the number of children reaching adulthood). The decline in the number of surviving offspring that was observed during the demographic transition is unlikely to follow from mortality decline. Mortality decline would have led to a reduction in the number of surviving offspring if the following implausible conditions would be met: (i) There exists a precautionary demand for children, i.e., individuals are significantly risk averse with respect to the number of surviving offspring. (ii) Risk aversion with respect to consumption is smaller than risk aversion with respect to fertility. (Evolutionary theory would suggest the opposite). (iii) Sequential fertility (i.e., replacement of non-surviving children) is modest. 


\section{B. The Rise in the Level of Income Per Capita}

The rise in income per capita prior to the demographic transition has led some researchers to argue that the demographic transition was triggered by the asymmetric effects of the rise in income per capita on households income and on the opportunity cost of raising children. Becker (1981) argues that the rise in income induced a fertility decline because the positive income effect on fertility was dominated by the negative substitution effect that was brought about by the rising opportunity cost of children. Similarly, he argues that the income elasticity with respect to child quality is greater than that with respect to child quantity, and hence a rise in income led to a decline in fertility along with a rise in the investment in each child.

This theory suggests that the timing of the demographic transition across countries in similar stages of development would reflect differences in income per capita. However, remarkably, the decline in fertility occurred in the same decade across Western European countries that differed significantly in their income per capita. In 1870, on the eve of the demographic transition, England was the richest country in the world, with a GDP per capita of \$3191 (measured in 1990 international dollars), (Maddison, 2001)). In contrast, Germany that experienced the decline in fertility in the same years as England, had in 1870 a GDP per capita of only $\$ 1821$ (i.e., 57\% of that of England). Sweden's GDP per capita of \$1664 in 1870 was 48\% of that of England, and Finland's GDP per capita of $\$ 1140$ in 1870 was only $36 \%$ of that of England, but their demographic transitions occurred in the same decade as well. The simultaneity of the demographic transition across Western European countries that differed significantly in their income per capita suggests that the high level of income reached by Western Europeans countries in the Post-Malthusian regime had a very limited role in the demographic transition.

\section{The Rise in the Demand for Human Capital}

The gradual rise in the demand for human capital in the second phase of the Industrial Revolution (and in the process of industrialization of less developed economies) and its close association with the timing of the demographic transitions, has led researchers to argue that the increasing role of human capital in the production process induced households to increase investment in the human capital of their offspring, ultimately leading to the onset of the demographic transition.

Galor and Weil (1999, 2000), argue that the acceleration in the rate of technological progress gradually increased the demand for human capital in the second phase of the Industrial Revolution, inducing parents to invest in the human capital of their offspring. The increase in the rate of technological progress and the associated increase in the demand for human capital brought about two effects on population growth. On the one hand, improved technology eased households' budget constraints and provided more resources for the quality as well as the quantity of children. On the other hand, it induced a reallocation of these increased resources toward child quality. In the early stages of the transition from the Malthusian regime, the effect of technological progress on parental income dominated, and the population growth rate as well as the average quality increased. Ultimately, further increases in the rate of technological progress that were stimulated by human capital accumulation induced a reduction in fertility rates, generating a demographic transition in which the rate of population growth declined along with an increase in the average level of education. Thus, consistent with historical evidence, the theory suggests that prior to the demographic transition, population growth increased along with investment in human capital, whereas the demographic transition brought about a decline in population growth along with a further increase in human capital formation. 
Galor and Weil's theory suggests that a universal acceleration in technological progress raised the demand for human capital in the second phase of the Industrial Revolution and generated a simultaneous increase in educational attainment and demographic transition across Western European countries that differed significantly in their levels of income per capita. Consistent with the theory, the growth rates (as opposed to the levels) of income per capita among these Western European countries were rather similar during their demographic transition, ranging from $1.9 \%$ per year over the period 1870-1913 in the UK, 2.12\% in Norway, 2.17\% in Sweden, to $2.87 \%$ in Germany. Moreover, the demographic transition in England was associated with a significant increase in the investment in child quality as reflected by years of schooling. Moreover, international trade and its differential effects on the demand for human capital had an asymmetric effect of the timing of the demographic transition (Galor and Mountford, 2006).

Evidence about the evolution of the return to human capital over this period is scarce and controversial. It does not indicate that the skill premium increased markedly in Europe over the course of the 19th century. The lack of clear evidence about the increase in the return to human capital over this period is an indication for the absence of a significant increase in the demand for human capital. Technological progress in the second phase of the Industrial Revolution brought about an increase in the demand for human capital, and indeed, in the absence of a supply response, one would have expected an increase in the return to human capital. However, the significant increase in schooling in the 19th century, and in particular the introduction of public education that lowered the cost of education, generated a significant increase in the supply of educated workers. Some of this supply response was a direct reaction of the increase in the demand for human capital, and thus may only operate to partially offset the increase in the return to human capital. However, the removal of the adverse effect of credit constraints on the acquisition of human capital (e.g., Galor and Zeira, 1993 and Galor and Moav, 2006), as reflected by the introduction of public education, generated an additional force that increased the supply of educated labor and operated towards a reduction in the return to human capital.

\section{C1. The Decline in Child Labor}

The effect of the rise in the demand for human capital on the reduction in the desirable number of surviving offspring was magnified via its adverse effect on child labor. It gradually increased the wage differential between parental labor and child labor inducing parents to reduce the number of their children and to further invest in their quality (Hazan and Berdugo, 2002). Moreover, the rise in the importance of human capital in the production process induced industrialists to support education reforms (Galor and Moav, 2006) and thus laws that abolish child labor (Doepke, 2004; Doepke and Zilibotti, 2005), reducing child labor and thus fertility.

\section{C2. The Rise in Life Expectancy}

The impact of the increase in the demand for human capital on the decline in the desirable number of surviving offspring has been reinforced by improvements in health and life expectancy. Despite the gradual rise in life expectancy prior to the demographic transition, investment in human capital was rather insignificant as long as a technological demand for human capital had not emerged. The technologically-based rise in the demand for human capital during the second phase of the Industrial Revolution and the rise in the expected length of productive life have increased the potential rate of return to investments in children's human capital, reinforcing the inducement for investment in education and the associated reduction in fertility rates. (Galor and Weil, 1999; Moav, 2005; Soares, 2005). 


\section{C3. Natural Selection and the Evolution of Preference for Offspring's Quality}

The impact of the increase in the demand for human capital on the decline in the desirable number of surviving offspring may have been magnified by cultural or genetic evolution in the attitude of individuals toward child quality. Galor and Moav (2002) propose that during the epoch of Malthusian stagnation that characterized most of human existence, individuals with a higher valuation for offspring quality (in the context of the quantity-quality survival strategies) gained an evolutionary advantage and their representation in the population gradually increased. The agricultural revolution facilitated the division of labor and fostered trade relationships across individuals and communities, enhancing the complexity of human interaction and raising the return to human capital. Moreover, the evolution of the human brain in the transition to Homo sapiens and the complementarity between brain capacity and the reward for human capital has increased the evolutionary optimal investment in the quality of offspring. The distribution of valuation for quality lagged behind the evolutionary optimal level and individuals with traits of higher valuation for their offspring's quality generated higher income and, in the Malthusian epoch a higher number of offspring. Thus, the trait of higher valuation for quality gained the evolutionary advantage. This evolutionary process was reinforced by its interaction with economic forces. As the fraction of individuals with high valuation for quality increased, technological progress intensified, raising the rate of return to human capital. The increase in the rate of return to human capital along with the increase in the bias towards quality in the population reinforced the substitution towards child quality, setting the stage for a more rapid decline in fertility along with a significant increase in investment in human capital and a transition to sustained economic growth.

\section{The Decline in the Gender Gap.}

The rise in the demand for human capital and its impact on the decline in the gender gap in the last two centuries could have reinforced a demographic transition and human capital formation. Galor and Weil $(1996,1999)$ argue that technological progress and capital accumulation complemented mental-intensive tasks and substituted for physical-intensive tasks in industrial production. In light of the comparative physiological advantage of men in physical-intensive tasks and women in mental-intensive tasks, the demand for women's labor input gradually increased in the industrial sector, decreasing monotonically the wage deferential between men and women. In early stages of industrialization, wages of men and women increased, but the rise in female's relative wages was insufficient to induce a significant increase in women's labor force participation. Fertility, therefore, increased due to the income effect that was generated by the rise in men's absolute wages. Ultimately, however, the rise in women's relative wages was sufficient to induce a significant increase in labor force participation. It increased the cost of child rearing proportionally more than households' income, generating a decline in fertility and a shift from stagnation to growth.

\section{E. The Old-Age Security Hypothesis}

The old-age security hypothesis (Caldwell, 1976) has been proposed as an additional mechanism for the onset of the demographic transition. It suggests that in the absence of capital markets that permit intertemporal lending and borrowing, children are assets that permit parents to smooth consumption over their lifetime. The process of development and the establishment of capital markets reduce this motivation for rearing children, contributing to the demographic transition. The significance of the decline in the role of children as assets in the onset of the demographic 
transition is questionable. The rise in fertility rates prior to the demographic transition, in a period of improvements in the credit markets, raises doubts about the significance of the mechanism. Furthermore, cross-section evidence (Clark and Hamilton, 2006) from the pre-demographic transition era indicates that wealthier individuals, that presumably had a better access to credit markets, had a larger number of surviving offspring 


\section{References}

Becker, Gary S. 1981. A Treatise on the Family. Cambridge: Harvard Press.

Caldwell,W.J. 1976. Toward a restatement of demographic transition theory. Population and Development Review 2, 321-366.

Clark, G. and G. Hamilton. 2006. Survival of the Richest. Journal of Economic History 66, 707736.

Doepke, M. 2004. Accounting for fertility decline during the transition to growth. Journal of Economic Growth 9, 347-383.

Doepke, Matthias and Fabrizio Zilibotti. 2005. The Macroeconomics of child labor regulation. American Economic Review 95, 1492-1524

Galor, O. and O. Moav. 2002. Natural selection and the origin of economic growth Quarterly Journal of Economics 117, 1133-1192.

Galor, O, and O. Moav. 2006. Das Human-Kapital: a theory of the demise of the class structure. Review of Economic Studies 73, 85-117.

Galor, O. and A. Mountford. 2006. Trade and the great divergence: the family connection. American Economic Review 96, 299-303.

Galor, O. and D.N. Weil. 1996 `The gender gap, fertility, and growth. American Economic Review 86, 374-387.

Galor, O. and D.N. Weil. 1999. From Malthusian stagnation to modern growth. American Economic Review 89, 150-154.

Galor, O. and D.N. Weil. 2000. Population, technology and growth: from the Malthusian regime to the demographic transition and beyond. American Economic Review 110, 806-828.

Galor, O. and J. Zeira. 1993. Income Distribution and Macroeconomics. Review of Economic Studies, 60, 35-52.

Hazan, M. and B. Berdugo. 2002. Child labor, fertility and economic growth. Economic Journal 112, 810-828.

Lagelof, N. 2003. Gender equality and long-run growth. Journal of Economic Growth 8, 403-426 Maddison, A. 2001 The World Economy: A Millennia Perspective. Paris: OECD.

Moav, Omer. 2005. Cheap children and the persistence of poverty. Economic Journal 115, 88110.

Soares, Rodrigo. R. 2005. "Mortality reductions, educational attainment, and fertility choice," American Economic Review 95, 580-601. 